\title{
PENINGKATAN PRODUKTIVITAS MENGGUNAKAN METODE LINE BALANCING PADA PROSES PENGEMASAN DI PT.XYZ
}

\author{
${ }^{1}$ Ismail Fardiansyah, ${ }^{2}$ Tri Widodo \\ ${ }^{1,2 .}$ Staff Pengajar Program Studi Teknik Industri, Fakultas Teknik \\ Universitas Muhammadiyah Tangerang \\ Jl. Perintis Kemerdekaan I/33, Cikokol, Kota Tangerang \\ Email : fardiansyahismail@yahoo.com, tiga_wd@yahoo.co.id
}

\begin{abstract}
A b s trak
PT.XYZ is a logistic service provider company. One of their division is a contract logistic. Contract logistic is division that maintain the warehouse of customer. One of Operation in warehouse is value added service (VAS) that additional services based on customer requirement one of VAS process in PT.XYZ is a packaging process. In order to meet the customer requirement, PT.XYZ should be productive and efficient in Operation. It can be happen through by line balancing. This paper explains about line balancing implementation in VAS process at PT.XYZ to increase productivity. Line balancing analysis in VAS process for current condition among others total cycle time are 131 second by 10 operator, it's impact to productivity by 106 box/operator/day, and line efficiency by $94 \%$. Based on this fact, improvement conducted through balancing workload and waste reduction to get optimum condition. The result of improvement are increase productivity by $104 \%$, increase line efficiency by 3\%, and cycle time reduction by $15 \%$. PT.XYZ need to continue conduct waste elimination and regular monitor of line balancing analysis to achieve sustainability of optimum productivity.
\end{abstract}

Kata Kunci : Line Balancing, Cycle time, Productivity, Line Efficiency, Waste Reduction.

\section{PENDAHULUAN}

Pada era modern sekarang ini situasi dunia industri manufaktur maupun jasa mengalami persaingan yang sangat ketat.

Hal ini memicu para produsen baik manufaktur ataupun jasa berkompetisi untuk dapat beroperasional secara efisien. Pengaturan dan perencanaan yang tidak tepat pada stasiun kerja dapat menimbulkan ketidakefisienan pada proses. Line balancing merupakan keputusan yang tepat untuk mengatasi hal tersebut.

Menurut adeppa (2015) line balancing dapat meningkatkan efisiensi pada proses dengan meminimalisir stasiun kerja, meminimalisir waktu siklus kerja, memaksimalkan beban kerja, dan meningkatkan fleksibilitas antar stasiun kerja. Menurut morshed dkk (2014) line balancing merupakan salah satu alat yang efektif untuk memperbaiki output dari suatu line atau proses melalui penurunan aktivitas yang tidak bernilai tambah dan penurunan waktu siklus kerja.

Proses pengemasan atau kiting pada PT.XYZ adalah proses baru yang merupakan permintaan dari customer dengan target sebesar 1200 box/hari. Proses pengemasan memiliki aktivitas antara lain : forming box, insert product to box, attach plastic, sealing, heating, checking. Total operator proses pengamasan ini sebanyak 11 orang. Rata-rata output selama bulan November adalah sebanyak 850 box/hari. Berangkat dari kondisi saat ini, PT.XYZ harus meningkatkan hasil output dengan sumber daya yang ada dengan kata lain peningkatan produktivitas harus dilakukan.

Pada penelitian ini, dilakukan analisa line balancing guna meningkatkan hasil output dan juga mengidentifikasi pemborosan yang terjadi dan bagaimana cara menyelesaikannya. Seperti yang dinyatakan oleh amardeep, dkk (2013) : kualitas dan kuantitas produk merupakan aspek terpenting dari permintaan pelanggan yang harus menjadi perhatian khusus bagi para pelaku 
industri kecil maupun menengah. Dan line balancing merupakan jalan untuk mencapai hal tersebut. Karena prinsip dasar dari line balncing adalah fokus kepada meminimalisir pemborosan.

Dengan analisa line balancing dapat diketahui waktu siklus setiap aktivitas, line balancing juga berupaya pada penurunan waktu siklus, yang akan berimbas kepada peningkatan efisiensi melalui penghematan waktu produksi. Malik, dkk (2011) : melalui penurunan waktu siklus dapat meningkatkan efisiensi, melalui penghematan waktu produksi dan berimbas pada peningkatan pelayanan pada pelanggan. Hasil penelitian yang dilakukan Malik, dkk (2011) menunjukkan bahwa penghematan waktu produksi dapat dilakukan sebesar $24 \%$.

Melihat fenomena ini, maka penelitian dilakukan dengan menganalisa proses pengemasan pada PT.XYZ dengan menggunakan line balancing dalam upaya peningkatan efisiensi dan output.

\section{METODE PENELITIAN}

\section{Pengumpulan Data}

Tahap ini mulailah dilakukan langkah-langkah pengumpulan data yang dibutuhkan untuk mencapai tujuan penelitian. Jenis data yang di ambil pun terbagi menjadi dua, yaitu data primer dan data sekunder.

\section{a. Pengumpulan Data Primer}

Data primer yang diambil antara lain adalah gemba yaitu dengan melihat kondisi aktual alur proses dan mengidentifikasi pemborosan yang terjadi. Lalu dengan melakukan pengukuran cycle time untuk seluruh aktitivitas pada proses pengemasan.

\section{b. Pengumpulan Data Sekunder}

Data sekunder yang diambil adalah data jumlah permintaan pelanggan, data jumlah karyawan.

\section{Analisa Line Balancing}

Pada tahap ini dilakukan analisa line balancing, dengan menampilkannya dalam bentuk diagram batang dan melihat potensi-potensi perbaikan.

\section{Perhitungan Efisiensi Lini dan Produktivitas Sebelum Improvement}

Tahap ini dilakukan perhitungan efisiensi lini dan produktivitas pada kondisi saat ini sebagai dasar untuk melakukan perbaikan.

\section{Rencana Perbaikan}

Tahap ini adalah membahas pemborosan yang terjadi pada saat melakukan gemba dan mereview alternatif perbaikan/ improvement. Selanjutnya adalah pembuatan rencana perbaikan dan eksekusi rencana tersebut.

\section{Perhitungan Efisiensi Lini dan Produktivitas Setelah Improvement}

Setelah improvement atau perbaikan dilakukan, maka tahapan ini adalah memeriksa hasil improvement melalui pengukuran efisiensi lini dan produktivitas setelah improvement.

\section{HASIL DAN PEMBAHASAN}

Proses pengemasan pada PT. XYZ memiliki aktivitas dengan langkah detail sebagai berikut:

Tabel 1. Aktivitas dan Langkah Detail Aktivitas Kondisi Saat ini

\begin{tabular}{|c|c|c|}
\hline No & Aktivitas & Langkah Detail Aktivitas \\
\hline 1 & Forming Box & $\begin{array}{c}\text { Forming Separator, forming inner, } \\
\text { insert product card }\end{array}$ \\
\hline 2 & Insert Product & Prepare Product, Insert Product \\
\hline 3 & Attach Plastic & Attach Plastic, put the neck holder \\
\hline 4 & Sealing & Sealing the plastic \\
\hline 5 & Heating & Arrange, Heat \& Checking \\
\hline
\end{tabular}



lain:

Hasil pengukuran cycle time masing-masing aktivitas pada proses pengemasan, antara

Tabel 2. Hasil Pengukuran Cycle Time kondisi saat ini

\begin{tabular}{|c|c|c|c|c|}
\hline No & Proses & $\begin{array}{c}\text { Total Waktu } \\
\text { (det/Box) }\end{array}$ & $\sum$ opr & $\begin{array}{c}\text { Cycle Time } \\
(\text { det })\end{array}$ \\
\hline 1 & Forming Box & 14 & 1 & 14 \\
\hline 2 & Insert Product & 13 & 1 & 13 \\
\hline 3 & Attach Plastic & 13 & 1 & 13 \\
\hline 4 & Sealing & 9 & 1 & 9 \\
\hline 5 & Heating & 82 & 6 & 14 \\
\hline
\end{tabular}

\section{Takt Time}

Hasil perhitungan takt time adalah sebagai berikut :

- Jumlah Jam Kerja yang tersedia perhari : 8 Jam atau 28.800 detik

- Jumlah permintaan pelanggan perhari : 1.300 box

$$
\text { Takt Time }=\frac{28.800 \mathrm{detik}}{1300 \text { box }}=22 \mathrm{det} / \mathrm{box}
$$

\section{Analisa Line Balancing}

Dari hasil pengukuran cycle time seluruh aktivitas proses dan perhitungan takt time, maka selanjutnya analisa dilakukan dengan menggunakan diagram batang, seperti yang terlampir pada diagram dibawah ini:

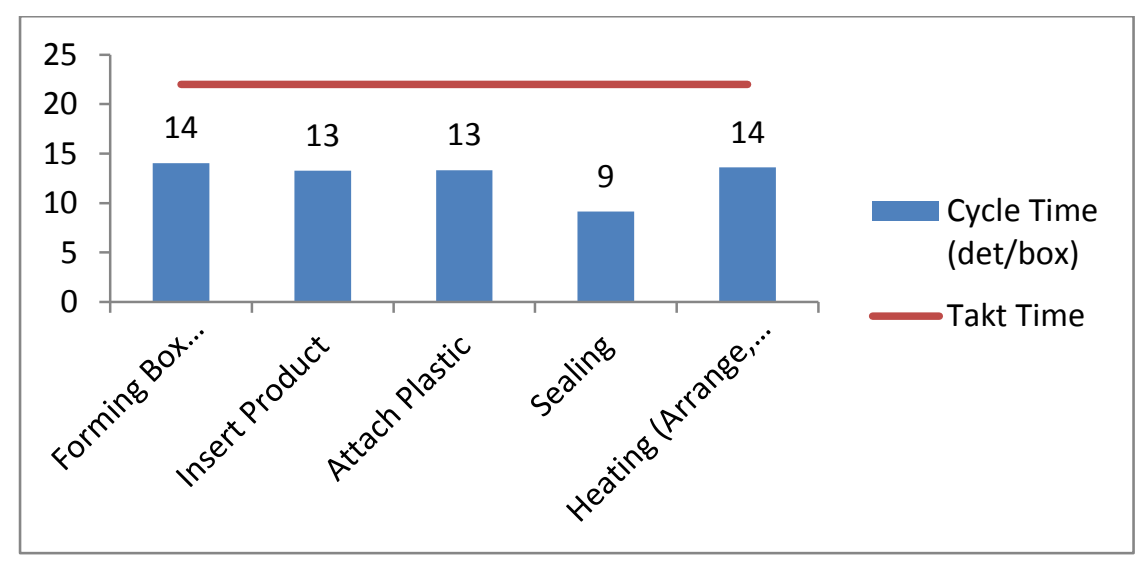

Gambar 1. Diagram Batang Cycle Time sebelum improvement

Dari diagram batang diatas dapat disimplkan bahwa dengan jumlah 10 operator, cycle time seluruh aktivitas berada di bawah takt time, yang artinya tidak ada bottle neck yang terjadi pada proses pengemasan. Adapun beberapa pemborosan ataupun potensi improvement yang didapat saat gemba atau observasi antara lain:

1. Rework, atau pengulangan proses heating karena kegagalan proses. Hal ini menyebabkan menurunnya output yang didapat.

2. Waiting, proses menunggu yang dilakukan oleh aktivitas sealing, dikarenakan proses sebelum dan sesudahnya memiliki cycle time yang lebih tinggi.

3. Motion, pemborosan pergerakan dari operator untuk melakukan proses dikarenakan penempatan material yang sulit untuk dijangkau. 


\section{Efisiensi Lini dan Produktivitas Sebelum Improvement}

Data yang didapat untuk menghitung efisiensi lini antara lain :

- Total cycle time : 131 detik

- Jumlah operator: 10 operator

- Cycle time terbesar : 14 detik

Efisiensi lini atau line efficiency pada proses pengemasan kondisi sebelum perbaikan adalah sebagai berikut :

$$
\begin{aligned}
\text { Efisiensi Lini } & =\frac{131 \text { Detik }}{10 \times 14 \text { detik }} \\
& =\text { Efisiensi Lini }=94 \%
\end{aligned}
$$

Data yang didapat untuk menghitung produktivitas antara lain :

- Output/hari : 1.068 box

- Jumlah operator : 10 operator

Dengan perhitungan sebagai berikut :

$$
\text { Produktivitas }=\frac{1068}{10}=106 \text { box }
$$

Sehingga produktivitas pada proses pengemasan adalah sebesar 106 box/operator/hari

\section{Rencana Perbaikan}

Dari hasil analisa line balancing dan pengukuran efisiensi line serta produktivitas, maka terdapat beberapa rencana perbaikan yang dilakukan guna meningkatkan produktivitas serta efisiensi pada proses pengemasan di PT XYZ. Perbaikan tersebut antara lain:

1. Penggabungan beberapa langkah detail dalam setiap aktivitas guna menyeimbangkan beban

\begin{tabular}{|c|c|c|}
\hline No & Aktivitas & Langkah Detail Aktivitas \\
\hline 1 & $\begin{array}{l}\text { Forming } \\
\text { Box }\end{array}$ & $\begin{array}{c}\text { Forming Separator, forming } \\
\text { inner, insert product card, } \\
\text { prepare product }\end{array}$ \\
\hline 2 & $\begin{array}{l}\text { Insert } \\
\text { Product }\end{array}$ & insert product, attach plastic, \\
\hline 3 & Sealing & $\begin{array}{c}\text { Put the neck holder, Sealing } \\
\text { the plastic }\end{array}$ \\
\hline 4 & Heating & (Arrange, Heat \& Checking) \\
\hline
\end{tabular}
kerja. Seperti dalam tabel dibawah ini.

Tabel 3. Langkah Aktivitas Setelah perbaikan

2. Eliminasi pemborosan yang terjadi, antara lain:

- Melakukan pelatihan untuk operator proses heating, untuk mengurangi kegagalan proses. serta penyediaan standard dan instruksi kerja yang jelas

- Relayout penempatan material agar lebih mudah di akses 


\section{Perhitungan Efisiensi Lini dan Produktivitas Setelah Improvement}

Hasil pengukuran cycle time setelah dilakukan perbaikan dapat dilihat pada tabel dibawah ini:

Tabel 4. Hasil Pengukuran Cycle Time Setelah Perbaikan

\begin{tabular}{|c|c|c|c|c|}
\hline No & Process & $\begin{array}{c}\text { Total Time } \\
\text { (Sec/box) }\end{array}$ & Eopr & $\begin{array}{c}\text { Cycle Time } \\
\text { (det) }\end{array}$ \\
\hline 1 & Forming Box & 18 & 1 & 18 \\
\hline 2 & Insert Product & 19 & 1 & 19 \\
\hline 3 & Sealing & 18 & 1 & 18 \\
\hline 4 & Heating & 56 & 3 & 18.7 \\
\hline
\end{tabular}

Dengan analisa menggunakan diagram batang seperti dibawah ini:

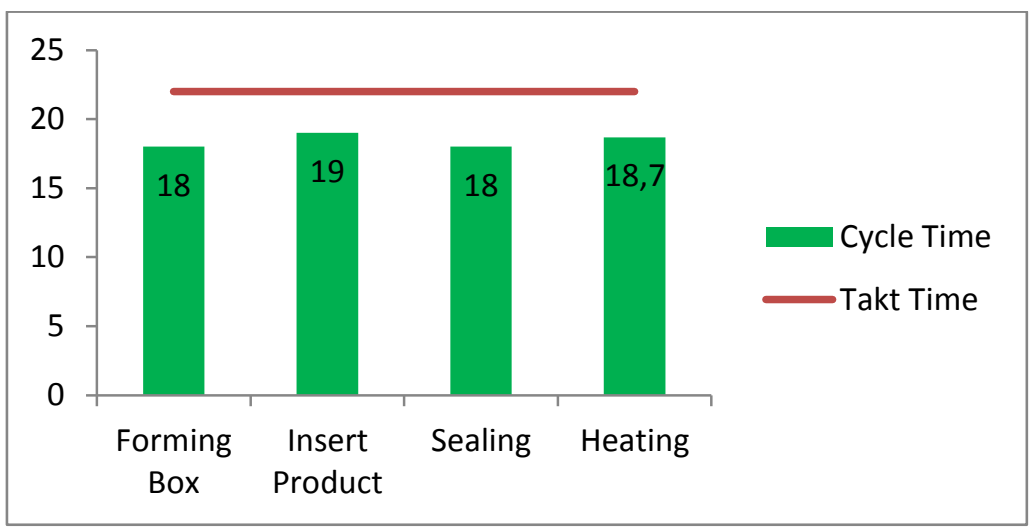

Gambar 2. Diagram Batang Cycle Time sebelum improvement

Dari tabel dan diagram diatas, dapat dilihat bahwa upaya eliminasi pemborosan dan penggabungan beberapa proses dapat mengurangi jumlah operator dengan catatan cycle time masih berada dibawah takt time. Sedangkan perhitungan efisiensi lini setelah improvement adalah sebagai berikut:

Efisiensi Lini $=\frac{111 \text { Detik }}{6 \times 19 \text { detik }}=97 \%$

Pencapaian output tertinggi setelah dilakukan perbaikan adalah 1.300 box perhari. Sehingga produktivitas setelah dilakukannya improvement yaitu :

$$
\text { Produktivitas }=\frac{1300}{6}=216 \text { box }
$$

Atau sebesar 216 box/operator/hari.

\section{Perbandingan Sebelum dan Sesudah Improvement}

Dengan melihat hasil penelitian diatas, dapat diketahui bahwa terjadi perubahan yang lebih baik antara sebelum dan sesudah perbaikan, antara lain :

1. Efektivitas jumlah operator

- Kondisi sebelum : 10 operator

- Kondisi sesudah : 6 operator

2. Peningkatan efisiensi lini

- Kondisi sebelum : $94 \%$

- $\quad$ Kondisi sesudah : $97 \%$ 
3. Produktivitas kerja

- Kondisi sebelum : 106 box/hari

- Kondisi sesudah : 216 box/hari

4. Total cycle time

- Kondisi sebelum : 131 detik

- Kondisi sesudah : 111 detik

\section{KESIMPULAN}

Kesimpulan yang dapat diambil dari penelitian ini antara lain :

1. Analisa line balancing dengan menyeimbangkan beban kerja dan eliminasi pemborosan dapat mengurangi jumlah operator sehingga meningkatkan produktivitas sebesar $104 \%$

2. Upaya penyeimbangan beban kerja dan eliminasi pemborosan juga dapat meningkatkan efisiensi lini sebesar 3\% dan mengurangi cycle time sebesar $15 \%$

Adapun saran yang bisa diberikan untuk perusahaan antara lain :

1. Upaya pengurangan pemborosan tidak berhenti setelah perbaikan ini selesai, namun harus dilakukan terus menerus.

2. Pengurangan jumlah operator pada proses pengemasan dapat dialokasikan untuk proses lain yang ada diperusahaan guna meningkatkan produktivitas perusahaan secara keseluruhan.

\section{DAFTAR PUSTAKA}

Adeppa, A,. (2015) A Study on Basic of Assembly line Balancing. International journal of emerging Technologies (special issue on NCRIET-2015) 6(2) : 294-297. ISSN: 2249-3255.

Amardeep., Rangaswamy, T, M., \& Gautham, J., (2013) Line Balancing of Single Model Assembly Line. International Journal of Innovative Research in Science, Engineering and Technology. Vol 2, issue 5, ISSN :2319-8753.

Baroto, Teguh., Perencanaan dan Pengendalian Produksi, Edisi 1, Ghalia Indonesia, 2002

Eryuruk, H, S,. kalaoglu, F., Baskak, M., (2008) Assembly Line Balancing in a clothing company. FIBRES \& TEXTILES in Eastern Europe Januray/March 2008, Vol.16 No.1 (66)

Firake, T. S., \& Inamdar, K, H., (2014) Productivity Improvement of Automotive Assembly Line Through Line Balancing. International Journal of Technical Research and Applications eISSN : 2360 - 8163, Vol.2, Issue 3 (May-June 2014), PP. 124-128

Liker, K. J., \& Meier, D. (2006). The Toyota Way Fieldbook a Practical Guide for Implementing toyota's 4Ps. New york : Mc Graw-Hill

Malik, s,. Pahwa, N, \& Malik, V., (2011) Implementation of Cycle Time Reduction Technique in Industry. International Journal of Manufacturing Science and Engineering International Science press' Vol.2 No.2 July-December 2011.

Morshed, N., \& Palash, S, K., (2014) Assembly Line Balancing to Improve Productivity Using Work Sharing Method in Apparel Industry. Global Journal of Researches in Engineering : G Industrial Engineering., Volume 14 Issue 3 version 1.0.

Rother, M., \& Shook, J. (2004). Learning to see : Value Stream mapping to create value and eliminate muda version 1.4. Cambridge : Lean Enterprise Institute.

Sarjono, H., (2001) Model Pengukuran Produktivitas Berdasarkan Pendekatan Rasion Output Per Input. Journal the winners, Vol.2 No.2 September 2001 : 130-136

Sharma, P., Thakar, G., \& Gupta, R, C., (2014) Evaluation of multi criteria assembly line balancing by MCDM approaches : a conceptual review. International Journal of Quality Research 8 (1) 87-106 ISSN 1800-6450

Umarani, P., \& Valase, K., (2017) Assembly Line Balancing in Textile Industry. International journal of scientific Research Engineering \& Technology (IJSRET) ISSN 2278 - 0882, Vol.6. Issue 4.

JIM, Vol. 3, No. 1, Januari 2018, pp.57-63 